\title{
THE DENSITY OF SOME SODA-LIME-SILICA GLASSES AS A FUNCTION OF THE COMPOSITION
}

\author{
By F. W. Glaze, J. C. Young, and A. N. Finn
}

\section{ABSTRACT}

Thirty-seven soda-silica and 22 soda-lime-silica glasses were made in platinum crucibles and the density and chemical composition of each glass were determined. From the data obtained equations were derived and a diagram was prepared showing the relations between density and composition of these glasses. Within the range of compositions considered, the diagram makes it possible to predict with considerable accuracy (1) the density of any glass from the composition and (2) the compositions of the various glasses having equal densities. Some evidence is presented indicating that the density of the soda-silica glasses is a simple function of certain soda-silica compounds which may be present in the glass.

CONTENTS

I. Introduction $\ldots \ldots \ldots 9$

II. The measurement of density 799

III. Data obtained and results

IV. Conclusions $\ldots \ldots$

\section{INTRODUCTION}

Studies of the relations between chemical composition and certain physical properties of glasses have received considerable attention in the past and a report on The Index of Refraction of Some Soda-LimeSilica Glasses as a Function of the Composition, by C. A. Faick and A. N. Finn, was recently published. ${ }^{1}$ In that report the purpose of this general study was given, the method of making the glasses was detailed, essential parts of the methods of chemical analysis were outlined, and the condition of annealing was described.

Since that report was published some additional glasses were made, and the present paper gives the results obtained with respect to density.

\section{THE MEASUREMENT OF DENSITY}

The samples prepared for the work on index of refraction were also used for density determinations and weighed approximately $20 \mathrm{~g}$ each. Since no samples were used that contained gaseous inclusions of sufficient magnitude to affect results, no corrections for "seeds" were necessary.

Density was determined by weighing the samples in air and then weighing them suspended in kerosene by means of a platinum wire basket which was connected with the balance beam by means of a single platinum wire. The suspending wire was covered with unbur- 
nished electroplated gold. The density of the kerosene was determined at first by means of a $25 \mathrm{ml}$ pycnometer; later it was determined by means of a plummet whose volume was $35.0300 \mathrm{ml}$ at $20^{\circ} \mathrm{C}$. and whose weight (corrected for buoyancy of air) was $43.7584 \mathrm{~g}$.

The density of the kerosene (average of 24 determinations) was 0.80870 ; the maximum change in density of the kerosene, based on observations extending over a period of 14 months, was 0.00028 . Measured densities of kerosene were computed to the density at $20^{\circ}$ C., using the coefficient 0.0007 per degree, which is sufficiently accurate if the temperature of observation does not differ from $20^{\circ} \mathrm{C}$. by more than $5^{\circ}$. When the densities of a large number of glasses were determined during the same day, the density of the kerosene was determined before and after the other determinations; the maximum observed change in any one day, probably resulting largely from unavoidable temperature variations, was 0.00014 ; the average change was 0.00005 .

The average variation in density observations, as determined from the results on six stable glasses, was 0.0003 , but since some of the other glasses were decidedly hygroscopic, the reported values for the latter may be in error by as much as 0.001 .

All weights were corrected for the buoyancy of air and results were computed to the density of water at $4^{\circ} \mathrm{C}$. The data obtained are given in Table 1 , as are also values computed by equation (3), differences between computed and observed values and temperatures at which the various glasses were annealed.

TABLE 1.-Composition, observed and computed densities, and annealing temperatures used for 59 soda-lime-silica glasses

\begin{tabular}{|c|c|c|c|c|c|c|c|}
\hline \multirow{2}{*}{ Glass No. ${ }^{1}$} & \multicolumn{3}{|c|}{ Composition } & \multicolumn{3}{|c|}{ Density } & \multirow{2}{*}{$\begin{array}{l}\text { Anneal- } \\
\text { ing tem- } \\
\text { perature } \\
\text { used }\end{array}$} \\
\hline & $\mathrm{SiO}_{2}$ & $\mathrm{Na}_{2} \mathrm{O}$ & $\mathrm{CaO}$ & Observed & $\begin{array}{l}\text { Com- } \\
\text { puted }\end{array}$ & $\mid \begin{array}{c}\text { Difierence } \\
\times 10^{4}\end{array}$ & \\
\hline - & $\begin{array}{r}\text { Per cent } \\
50.22 \\
50.51 \\
51.61 \\
52.60 \\
53.62\end{array}$ & $\begin{array}{r}\text { Per cent } \\
49.78 \\
49.49 \\
48.39 \\
47.40 \\
46.38\end{array}$ & Per cent & $\begin{array}{l}2.5656 \\
2.5640 \\
2.5607 \\
2.5537 \\
2.5515\end{array}$ & $\begin{array}{l}2.5666 \\
2.5654 \\
2.5602 \\
2.5555 \\
2.5508\end{array}$ & $\begin{array}{r}-10 \\
-14 \\
+5 \\
-18 \\
+7\end{array}$ & $\begin{array}{r}{ }^{\circ} C . \\
450 \\
450 \\
440 \\
460 \\
450\end{array}$ \\
\hline $\begin{array}{l}6(1) \\
7 \\
8 \\
9 \\
10\end{array}$ & $\begin{array}{l}54.14 \\
56.56 \\
57.45 \\
58.98 \\
59.69\end{array}$ & $\begin{array}{l}45.86 \\
43.44 \\
42.55 \\
41.02 \\
40.31\end{array}$ & & $\begin{array}{l}2.5475 \\
2.5383 \\
2.5318 \\
2.5266 \\
2.5240\end{array}$ & $\begin{array}{l}2.5484 \\
2.5372 \\
2.5330 \\
2.5261 \\
2.5226\end{array}$ & $\begin{array}{r}-9 \\
+11 \\
-12 \\
+5 \\
+14\end{array}$ & $\begin{array}{l}420 \\
450 \\
430 \\
460 \\
450\end{array}$ \\
\hline $\begin{array}{l}11 \\
13(6) \\
15(7)\end{array}$ & $\begin{array}{l}59.71 \\
59.97 \\
62.77 \\
62.86 \\
63.06\end{array}$ & $\begin{array}{l}40.29 \\
40.03 \\
37.23 \\
37.14 \\
36.94\end{array}$ & & $\begin{array}{l}2.5228 \\
2.5208 \\
2.5071 \\
2.5044 \\
2.5038\end{array}$ & $\begin{array}{l}2.5224 \\
2.5210 \\
2.5062 \\
2.5058 \\
2.5047\end{array}$ & $\begin{array}{l}+4 \\
-2 \\
+9 \\
-14 \\
-9\end{array}$ & $\begin{array}{l}470 \\
430 \\
470 \\
440 \\
440\end{array}$ \\
\hline $\begin{array}{l}16(9) \\
17(10) \\
18 \\
19(11) \\
20(12)\end{array}$ & $\begin{array}{l}65.30 \\
65.32 \\
66.52 \\
67.14 \\
69.65\end{array}$ & $\begin{array}{l}34.70 \\
34.68 \\
33.48 \\
32.86 \\
30.35\end{array}$ & & $\begin{array}{l}2.4890 \\
2.4924 \\
2.4865 \\
2.4807 \\
2.4644\end{array}$ & $\begin{array}{l}2.4930 \\
2.4928 \\
2.4862 \\
2.4819 \\
2.4650\end{array}$ & $\begin{array}{r}-40 \\
-4 \\
+3 \\
-12 \\
-6\end{array}$ & $\begin{array}{l}450 \\
480 \\
480 \\
500 \\
515\end{array}$ \\
\hline $\begin{array}{l}21(13) \\
22(14) \\
23(15) \\
24 \\
25\end{array}$ & $\begin{array}{l}70.21 \\
70.44 \\
72.15 \\
72.33 \\
74.16\end{array}$ & $\begin{array}{l}29.79 \\
29.56 \\
27.85 \\
27.67 \\
25.84\end{array}$ & & $\begin{array}{l}2.4612 \\
2.4603 \\
2.4488 \\
2.4479 \\
2.4343\end{array}$ & $\begin{array}{l}2.4612 \\
2.4597 \\
2.4483 \\
2.4472 \\
2.4351\end{array}$ & $\begin{array}{r}0 \\
+6 \\
+5 \\
+7 \\
-8\end{array}$ & $\begin{array}{l}525 \\
525 \\
525 \\
500 \\
505\end{array}$ \\
\hline
\end{tabular}

1 Figures in parentheses are the numbers of the same glasses in the refractivity paper. 
data. In this case the need for straight lines rather than a continuous curve again became evident, but the changes in slope of the straight lines drawn through the plotted data were not decidedly pronounced.

When, bowever, specific volumes (reciprocal of density) were plotted against silica, a very satisfactory series of straight lines could be drawn through the plotted data. (Fig. 1.) The intersections of these lines occurred at approximately 59.4, 66.3, and 74.9 per cent silica. These values correspond closely to three simple molecular ratios of soda to silica, namely, $4: 6,3: 6$, and $2: 6$. Of these the only
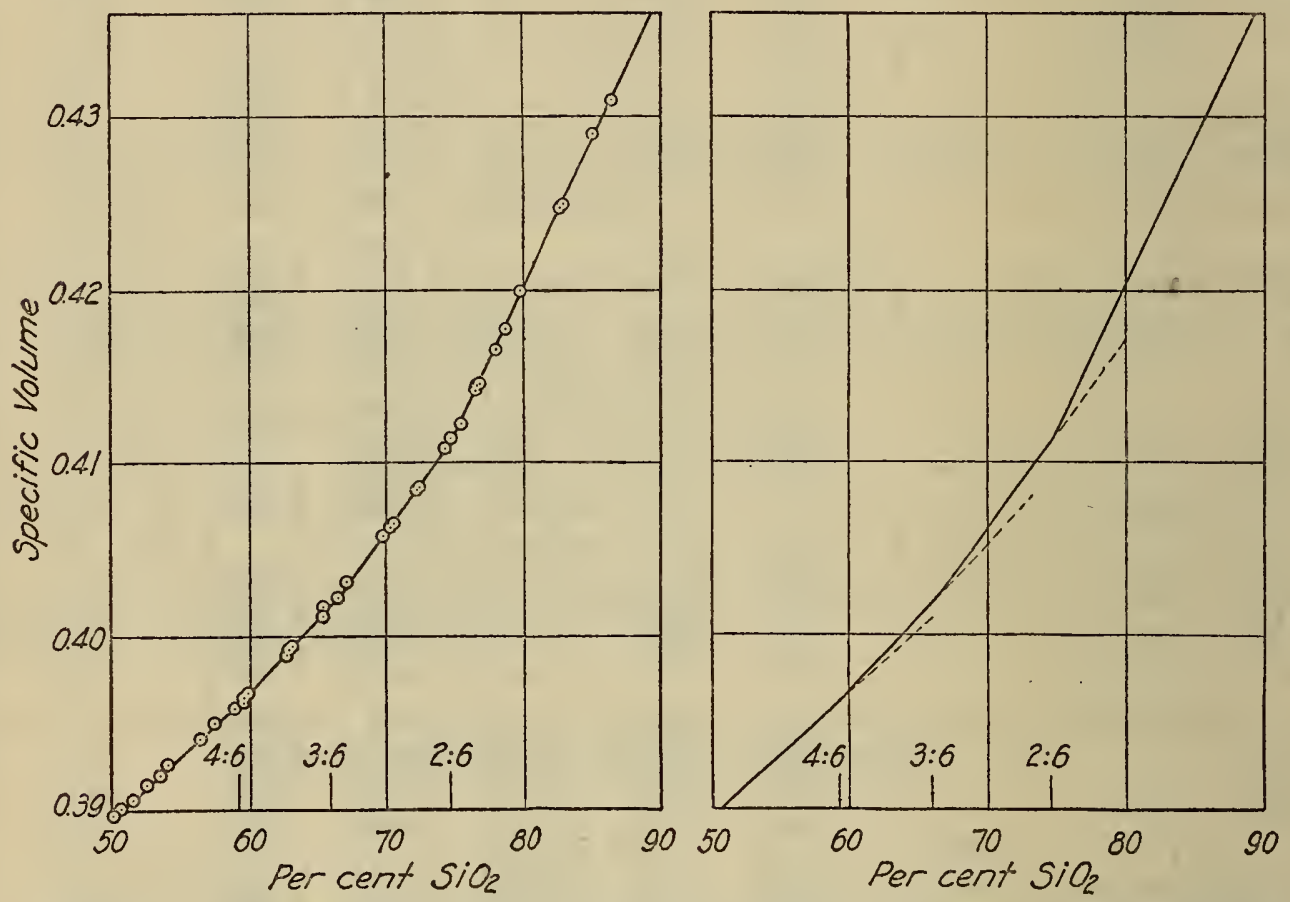

FIGURE 1.-Diagram showing relation between composition and specific volume of some soda-silica glasses; three molecular ratios of soda to silica are also indicated

All reported observations are plotted in the graph at the left and are omitted in the graph at the right; the lines in boih these graphs are identical and the dotted extensions are added, in the right-hand graph, to emphasize the change in slope of the various sections

one obtained in a crystalline state is the $3: 6$ compound $^{2}$ (ordinarily written 1:2).

Equations of the form $\frac{1}{D}=a+b A$, in which $A$ is the percentage of

silica, can be used to express the four straight lines in Figure 1. Since such equations involve only one constituent of the binary glasses they could not be readily applied to more complex glasses; consequently the initial equations were converted, through the relation $A+B=100$, to the form

$$
\frac{1}{D}=\alpha A+\beta B
$$

in which $\alpha$ and $\beta$ are empirical constants having different values for the different ranges of composition, as shown in Table 2. A simul-

'Morey, G. W., and Bowen, N. L., The Binary System Sodium Metasilicate-silica, J. Phys. Chem., vol. 28 , No. 11, pp. 1167-1179, 1924. 
taneous solution of each adjacent pair of equations gives the indicated silica limits.

In general the data on the soda-lime glasses were treated as if the combined amount of soda and lime were all soda, and a value for $\frac{1}{D}$ for each glass was computed from equation (2), using appropriate constants. The differences between these computed values and the observed specific volumes were plotted as functions of the percentage of lime, $C$, and four equations of the form

$$
f(C)=k C+\gamma^{\prime} C^{2}
$$

were obtained, $k$ and $\gamma^{\prime}$ being empirical constants. Each of these equations, when added to its corresponding soda-silica equation, gives the completed form

$$
\frac{1}{D}=\alpha A+\beta(B+C)+k C+\gamma C^{2}
$$

or

$$
\bar{D}=\alpha A+\beta B+\gamma C+\gamma^{\prime} C^{2}
$$

in which $A, B$, and $C$ represent the percentages of silica, soda and lime, respectively, and $\alpha, \beta, \gamma$, and $\gamma^{\prime}$ are empirical constants having the values indicated in Table 2 .

It is evident that this procedure assumes initially that the lines of demarcation $\left(a a^{\prime}, b b^{\prime}\right.$, and $c c^{\prime}$, in fig 2 ) will lie along constant silica lines, but a simultaneous solution of each adjacent pair of equations (3) gives the following values of the silica limits for the glasses containing lime:

$$
\begin{aligned}
& A_{a}=59.4-0.23 C+0.032 C^{2} \text { (indicated by } a a^{\prime} \text { in fig. 2) } \\
& A_{b}=66.3+.15 C-.004 C^{2} \text { (indicated by } b b^{\prime} \text { in fig. 2) } \\
& A_{c}=74.9-.017 C^{2} \text { (indicated by } c c^{\prime} \text { in fig. 2) }
\end{aligned}
$$

in which $A_{a}, A_{b}$, and $A_{c}$ represent, respectively, the percentages of silica for the lines $a a^{\prime}, b b^{\prime}$, and $c c^{\prime}$.

In arriving at the best values for $\gamma$ and $\gamma^{\prime}$, therefore, it was necessary with some glasses near the limiting silica values to depart from the general procedure outlined by using an adjacent set of values of $\alpha$ and $\beta$ in anticipation of the final positions of the lines of demarcation. The proper selection of the values of $\alpha$ and $\beta$ could only be determined by trial. These curved lines are preferred to the straight lines indicated in the refractivity paper because density changes with composition are approximately seven times greater than corresponding refractivity changes, and, hence, give a better criterion of the location of these lines. Equation (3) and the constants in Table 2 were used in computing data to draw the lines of equal density shown in Figure 2 in which all the experimental glasses are indicated. As additional data are obtained, however, it may be necessary to make other changes in the location of these lines of demarcation. 





TABLE 2.-Silica limits and values of corresponding constants for equations (2) and (B)

\begin{tabular}{|c|c|c|c|c|}
\hline Silica limits, per cent silica & $\alpha$ & $\beta$ & $\gamma$ & $\gamma^{\prime}$ \\
\hline $\begin{array}{l}50 \text { (?) to } A_{a} \\
\mathrm{~A}_{a} \text { to } A_{b} \\
\mathrm{~A}_{b} \text { to } A_{e} \\
\mathrm{~A}_{c} \text { to } 100.0\end{array}$ & $\begin{array}{r}0.0042520 \\
.0043028 \\
.0043922 \\
.0045400\end{array}$ & $\begin{array}{r}0.0035370 \\
.0034628 \\
.0032872 \\
.0028460\end{array}$ & $\begin{array}{r}0.002545 \\
.002500 \\
.002285 \\
.001844\end{array}$ & $\begin{array}{r}0.0000080 \\
.0000040 \\
.0000050 \\
.0000148\end{array}$ \\
\hline
\end{tabular}

\section{CONCLUSION}

Considering the data on the soda-silica glasses only (and disregarding the trend of specific volume changes in the soda-lime glasses), it is difficult to avoid the conclusion that the increment in specific volume of any of these glasses between the end members of the group (indicated in Table 2) in which that particular glass lies, is directly proportional to the increment in silica. In other words, the data suggest that the soda-silica glasses, in the range studied, should be regarded either as simple compounds or as simple mixtures of two adjacent compounds.

Washington, August 3, 1932.

$$
145879-32-7
$$

